\title{
AVALIAÇÃO FORMATIVA: UM OLHAR DISCENTE/DOCENTE SOBRE AS PRÁTICAS DE PROFESSORES DOS ANOS INICIAIS
}

\author{
FORMATIVE EVALUATION: A STUDENT / TEACHER LOOK AT THE \\ PRACTICES OF TEACHERS IN THE EARLY YEARS
}

\author{
Karine Cerdeira dos Santos \\ Universidade Federal do Pará - UFPA \\ cerdeira335@gmail.com \\ Valéria Risuenho Marques \\ Universidade Federal do Pará - UFPA \\ vrisuenho@ufpa.br
}

\begin{abstract}
Resumo
Este trabalho apresenta resultados parciais do projeto de pesquisa intitulado "Avaliação das aprendizagens em aulas de matemática nos anos iniciais: percepções de graduandos" e tem como objetivo identificar, sob a ótica de avaliação formativa, o processo de avaliação de professores de turmas do $4^{\circ}$ e $5^{\circ}$ anos iniciais e discuti-lo. A pesquisa é de caráter descritivo está organizada em: estudos teóricos, observação, grupo de discussão, realização de entrevista e análise de material empírico. Participaram do projeto 10 graduandos do $7^{\circ}$ semestre do curso de Licenciatura Integrada em Ciências, Matemática e Linguagens da UFPA, Belém-PA, que cursavam o tema Estágio de Docência II. Neste trabalho, analisamos o material empírico constituído da realização de entrevistas, os resultados apontam que, a partir das concepções desses graduandos, os professores das escolas alvo da pesquisa, ainda enxergam a avaliação dissociada do processo de ensino-aprendizagem, além de concretizar a prova como principal instrumento para avaliar. Quanto aos graduandos, os resultados mostram que houve aprendizado em relação a três aspectos: a ampliação dos conceitos relacionados à avaliação formativa; percepção sobre indissociabilidade entre ensino-aprendizagem-avaliação e ampliação do conhecimento de instrumentos de avaliação. Palavras-chave: Práticas e instrumentos de avaliação. Anos Inicias. Formação inicial.
\end{abstract}

\begin{abstract}
This work presents partial results of the research project entitled "Assessment of learning in mathematics classes in the early years: perceptions of undergraduate students" and aims to identify, from the perspective of formative assessment, the process of evaluating teachers in classes from the 4th and Initial 5th years and discuss it. The research, of a descriptive character, was organized in: theoretical studies, observation, discussion group, interview and analysis of the empirical material. Ten undergraduate students from the 7th semester of the Integrated Licentiate in Science, Mathematics and Languages course at UFPA, Belém-PA, participated in the project, who were studying the subject of Teaching Internship II. In this text, the empirical material constituted by conducting interviews will be analyzed. The analysis of the research showed that,
\end{abstract}

ReviSeM, Ano 2020, No. 2, p. 307-327 
based on the conceptions of these graduates, the teachers of the schools targeted by the research still see the dissociated evaluation of the teaching-learning process, in addition to making the test the main instrument to evaluate. As for undergraduates, we show that there was learning in relation to three aspects: the expansion of concepts related to formative assessment; perception of inseparability between teaching-learning-assessment and expanding knowledge of assessment tools.

Keywords: Assessment practices and instruments. Early Years. Initial formation.

\section{INTRODUÇÃO}

Avaliação, no âmbito educacional, tem sido objeto de estudo de pesquisadores em diferentes áreas. Dentre os vários enfoques, há a análise de aspectos envoltos na realização de avaliações em larga escala e a compreensão de características intrínsecas às concepções de avaliação e aos resultados que se evidenciam ao focar o olhar para as aprendizagens dos estudantes.

Nesta perspectiva, este trabalho integra o projeto de pesquisa intitulado "Avaliação das aprendizagens em aulas de matemática nos anos iniciais: percepções de graduandos" que envolve futuros professores em discussões, as quais objetivam promover tanto a compreensão da avaliação como um fenômeno inerente ao processo de ensino e de aprendizagem, quanto a reflexão sobre as concepções presentes nas propostas de ensino dos professores observados durante o período do estágio, no que diz respeito às práticas avaliativas e aos instrumentos utilizados para avaliar os alunos em turmas dos anos iniciais do Ensino Fundamental.

Sobre o tema abordado, a pesquisa de Calzavara (2011) - intitulada "As práticas avaliativas e os registros de resultados nos anos iniciais do ensino fundamental: um estudo de caso" - propôs-se a investigar as práticas avaliativas usuais no cotidiano analisando-as e a conhecer as formas utilizadas para comunicar os processos avaliativos dos alunos de turmas dos anos iniciais do ensino fundamental de uma escola da rede pública municipal do Rio de Janeiro. Os resultados apontaram que: a. embora os professores utilizassem diferentes instrumentos avaliativos, a avaliação informal possuía um importante papel no processo avaliativo dos estudantes e b. os instrumentos utilizados para comunicar o processo avaliativo não se mostraram significativos para o acompanhamento das trajetórias individuais de aprendizagem de cada indivíduo. 
Destaca-se também, em nossos estudos, a pesquisa de Santos (2016), intitulada "Práticas Avaliativas no contexto dos anos iniciais: acontecimentos, circunstâncias e significados para refletir sobre a própria prática" que teve como propósito investigar as experiências vividas, na perspectiva de compreender possíveis contribuições sobre avaliação das aprendizagens no processo formativo a fim de possibilitar a formulação de ações pedagógicas no âmbito da avaliação da aprendizagem, a partir de uma perspectiva formativa. Como um dos resultados a autora indica que: "os professores tendo a coordenação como elemento de suporte para dialogar sobre as aprendizagens, são juntamente com os alunos os grandes responsáveis em construir novas práticas no que se refere às avaliações para as aprendizagens" (SANTOS, 2016, p. 74).

Considerando as leituras destes e de outros trabalhos (SANTOS, 2012; MARQUES, 2013; ALVES, 2016), é notório que há a evidência de avanços nesta área, no entanto, não houve a identificação de pesquisas cujo enfoque partisse das concepções de graduandas acerca do que observaram na prática de professores durante o período estágio.

Nesta pesquisa, ancoramo-nos em Fernandes (2009), ao propor a avaliação formativa alternativa; Borralho, Lucena e Brito (2015), autores que compreendem como principal objetivo da avaliação a melhoria das aprendizagens; Perrenoud (1999) que propõe a regulação aos níveis das aprendizagens, individualizando-as através da avaliação formativa e Silva (2004) que sugere a ressignificação das concepções e das práticas avaliativas.

Enquanto estratégia metodológica, o estudo foi organizado em etapas, a saber: estudos teóricos, observação, grupo de discussão, realização de entrevista e análise do material empírico. A questão que nos norteou foi: "os professores do $4^{\circ}$ e $5^{\circ}$ anos de escolas estaduais de Belém/PA utilizam na prática a avaliação formativa?" Como objetivo do estudo, propusemo-nos a identificar em que termos graduandos participantes do projeto compreenderam a relevância de se ampliar o entendimento sobre avaliação formativa.

Participaram do estudo 10 graduandos, do $7^{\circ}$ semestre do curso de Licenciatura Integrada em Ciências, Matemática e Linguagens, durante o primeiro semestre de 2018, os quais se envolveram em estudos, observação e em reuniões do grupo de discussão. 
Parte dos resultados das transcrições das sessões de grupo de discussão foram analisadas e constam em Ribeiro e Marques (2019).

Nesta pesquisa, serão analisados, como material empírico, as interações ocorridas com dois graduandos colaboradores do projeto, por meio da realização de entrevistas semi-estruturadas que foram realizadas no segundo semestre de 2018, gravadas, com as devidas autorizações, e, posteriormente, transcritas.

Dispondo do material empírico constituídos das entrevistas, evidenciamos: ampliação dos conceitos relacionados à avaliação formativa; percepção sobre uma avaliação intrínseca a um mesmo processo ensino-aprendizagem-avaliação e ampliação do conhecimento de instrumentos de avaliação. Este texto traz discussões e análises feitas, com o intuito da consecução do objetivo da pesquisa.

\section{AVALIAR É ...}

A avaliação é um ato inerente ao indivíduo, usada a todo o momento no cotidiano. Avalia-se tudo, desde possibilidades, atributos, desempenhos, dentre outros. Tudo acaba passando por uma avaliação, por um julgamento, e, ao mesmo tempo, ora nos encontramos na posição de avaliador, ora na de avaliado. Nesta pesquisa, optamos por direcionar o olhar para aspectos da avaliação no ambiente escolar, um assunto que é discutido desde muito tempo em diversas perspectivas e vem sendo a cada dia ressignificado por agregar novos olhares no sentido de abranger uma avaliação para melhorar as aprendizagens.

Pautada em uma concepção de avaliação que se ocupa da melhoria das aprendizagens, Hoffman considera que

Avaliar nesse novo paradigma é dinamizar oportunidades de ação-reflexão, num acompanhamento permanente do professor e este deve propiciar ao aluno em seu processo de aprendizagem, reflexões acerca do mundo, formando seres críticos libertários e participativos na construção de verdades formuladas e reformuladas (1993, p. 134).

Em consonância com a autora, ao avaliar, o avaliador precisa dar condições ao avaliado de se rever, de refletir sobre seu percurso, de ter clareza sobre aonde é necessário chegar, para compreender o que ainda carece ser feito. É uma tarefa realizada no cotidiano, pautada em observações que não se restringem às verificações ocorridas apenas nas semanas de provas. 
De acordo com Luckesi (2011), avaliar é objetivar. Sobretudo, auxiliar no processo de aprendizagem dos alunos e no ato de aprender, de se desenvolver. Dessa forma, a avaliação passa a ser uma prática que se aproxima, em aspectos, de um processo investigativo, no que diz respeito à qualidade do aprendizado, direcionada ao diagnóstico de problemas para propor soluções que viabilizem melhores resultados no aprendizado.

Considerando algumas concepções sobre avaliação, de acordo com Libâneo (1994), faz-se necessário conhecer as dimensões da avaliação presentes nas salas de aula, a saber: diagnóstica, somativa e formativa. A diagnóstica tem como papel fundamental verificar quem absorveu os conhecimentos e adquiriu as habilidades necessárias; a somativa está atrelada a uma certificação, tende a enfatizar a classificação e, por fim, a formativa que visa à integralização do ensino, da aprendizagem e da avaliação para uma aprendizagem mais significativa.

Neste trabalho, optamos por discutir aspectos concernentes à avaliação formativa, compreendendo que as outras dimensões são igualmente relevantes.

\section{AVALIAÇÃO FORMATIVA}

$\mathrm{Na}$ concepção de avaliação formativa, proposta por autores como Fernandes (2009), Perrenoud (1999) e Libâneo (1994), podemos compreender, assim como Borralho, Lucena e Brito (2015), uma avaliação interna que se interessa pelas melhorias das aprendizagens dos alunos. De modo semelhante, Catani e Gallego (2009) consideram uma avaliação indissociada do processo de aprendizagem dos alunos visando à formação e não a classificação.

A avaliação formativa emerge, portanto, na perspectiva de se romper com a concepção de avaliação que se envolve apenas com a classificação, com o ranqueamento e com a certificação. Visualiza a perspectiva de se cuidar do processo, do dia-a-dia, de modo que, ao se destinar esforços para a melhoria dos resultados alcançados durante esse processo, possamos conseguir uma certificação com qualidade. A isso Perrenoud (1999) propõe uma regulação que se destina ao nível das aprendizagens, de modo a individualizá-las.

A avaliação formativa está diretamente associada à necessária reflexão do docente em que, segundo Borralho, Lucena e Brito, 
O cotidiano das aulas, para a maneira que se planeja e organiza o ensino, para as estratégias de ensino e as manifestações dos alunos sobre elas, para a qualidade e diversidade de instrumentos de avaliação usados nos processos de ensino-aprendizagem (2015, p. 30).

Atentar para algumas etapas que podem influenciar na avaliação das aprendizagens é relevante, pois a avaliação formativa necessita de um aprimoramento de seus respectivos instrumentos que vão do teste minucioso, descrevendo de modo extensivo um nível de alcance e competência, a observação no seu próprio espaço, dos métodos de trabalho, dos procedimentos e dos processos intelectuais do aluno (PERRENOUD, 1999).

Ao discutir sobre avaliação formativa, Silva (2004) denomina-a de formativareguladora e destaca pilares e dimensões. Para esse autor, três pilares sustentam esta perspectiva:

O primeiro pilar de uma avaliação formativa/reguladora é a valorização das diferenças que nos tornam humanos, e para isso, é preciso acreditar tenazmente nas possibilidades de todas as crianças e jovens aprenderem (...) intensificar a observação e o diálogo, dedicar mais atenção e mais tempo, criar e experimentar novas estratégias pedagógicas até se dar conta de ajudar a quem mais precisa da escola e do professor. Não se trata de escola para todos, mas de aprendizagem digna para todos (SILVA, 2004, p. 13).

Nesse primeiro pilar o estudioso destaca a relevância de se compreender e valorizar as diferenças. Todos somos diferentes e, diante disto, enquanto professores, precisamos acreditar no potencial de todas as crianças para aprender. Para isso, cabe a diversificação de estratégias que sejam capazes de alcançar a todos que estão sob nossa responsabilidade em sala de aula.

De acordo com o segundo pilar,

avaliação formativa é uma escola sedutora, uma escola acolhedora das várias dimensões do aluno: afetiva, ideológica e que se organize para trabalhar a partir e em delas (...) uma escola que nos convide, que nos inclua, nos seduza, nos encante. Uma escola pensada e vivida para melhor acolher meninos e meninas, principalmente os de periferia, pois são eles que mais precisam de educação escolar para se inserir na sociedade de forma digna (SILVA, 2004, p. 29).

O segundo pilar fala da "escola sedutora", uma escola que acolhe, na qual os meninos e meninas queiram estar porque se sentem partícipes, porque veem essa escola como uma possibilidade de serem inseridos nas práticas e atividades da sociedade.

No que se refere ao terceiro pilar,

é a formação do professor como intelectual reflexivo transformador (...) a 
referência a "capacidade de interpretar" do educador, pois é o que caracteriza, em essência, o significado de avaliação formativa-reguladora - o professor como decifrador dos percursos de construção de conhecimento por que passa $o$ aluno, intérprete de suas produções, de erros e acertos, permanentemente aberto ao diálogo, duvidando sempre de suas "certezas" (SILVA, 2004, 13).

O último e terceiro pilar deixa em voga o professor, mas um professor que reflete, não limita, dialoga, procura compreender aspectos do percurso formativo de seus alunos, sempre atendo aos erros e acertos, com vistas a encaminhar práticas que efetivamente contribuam para a melhoria das aprendizagens desses alunos. Para Silva, "sua formação é, portanto, igualmente uma consequência dos desafios que enfrenta e das possibilidades de interlocução permanente e continuada com seus pares sobre tais desafios" (2004, p. 14).

Um aspecto que se destaca na concepção de avaliação formativa-reguladora (SILVA, 2004) é a afirmação de que a essência da avaliação está no acompanhar de forma interativa e "regula-tivamente" sobre os processos pedagógicos, de modo que se possa verificar se estão sendo, de fato, atingidos.

A perspectiva da avaliação formativa alternativa, proposta por Fernandes (2009), trata-se de uma avaliação "interativa, situada nos contextos vividos por professores e alunos, centrada na regulação e na melhoria das aprendizagens, participativa, transparente e integrada nos processos de ensino e de aprendizagem" (FERNANDES, 2009, p. 56).

$\mathrm{Na}$ concepção da avaliação formativa alternativa, professores e alunos partilham responsabilidades em termos de avaliação e regulação das aprendizagens. Essa partilha requer, dentre outros aspectos, que os professores possam:

- Organizar o processo de ensino;

- Propor tarefas apropriadas aos alunos;

- Definir previa e claramente os propósitos e a natureza do processo de ensino e avaliação;

- Diferenciar suas estratégias;

- Utilizar um sistema permanente e inteligente de feedback que apoie efetivamente os alunos na regulação das aprendizagens;

- Ajustar sistematicamente o ensino de acordo com as necessidades; e

- Criar um adequado clima de comunicação interativa entre os alunos e entre estes e os professores (FERNANDES, 2009, p. 59).

O papel do professor, na perspectiva defendida por Fernandes (2009), é o de organizador do processo de ensino. Precisa propor tarefas apropriadas aos alunos, deixando evidentes os objetivos e a natureza do processo. Além disto, é atento à diversificação de estratégias, procurando disponibilizar feedback que dê condições aos 
alunos perceberem onde estão e aonde precisam chegar em termos do nível de aprendizagem almejado.

No que se refere à responsabilidade dos alunos:

- Participar ativamente nos processos de aprendizagem e de avalição;

- Desenvolver as tarefas que lhes são propostas pelos professores;

- Utilizar o feedback que lhes é fornecido pelos professores para regularem suas aprendizagens;

- Analisar seu próprio trabalho mediante seus processos metacognitivos e da autoavaliação;

- Regular suas aprendizagens tendo em conta os resultados da autoavaliação e de seus recursos cognitivos e metacognitivos;

- Partilhar seu trabalho, suas dificuldades e seus sucessos com o professor e com os colegas; e

- Organizar seu próprio processo de aprendizagem (FERNANDES, 2009, p. 59-60).

Aos alunos é atribuída a necessidade de participarem ativamente do processo de ensino e aprendizagem, regulando-o, envolvendo-se no desenvolvimento de atividades e fazendo autoavaliação desse processo.

A avaliação formativa alternativa solicita partilha no que diz respeito às responsabilidades entre professor e aluno sobre a matéria de avaliação e de regulação das aprendizagens. Nesta perspectiva, destacam-se os seguintes elementos: regulação do ensino e aprendizagem, autorregulação da aprendizagem e o feedback.

A regulação do ensino e aprendizagem, conforme Fernandes, "é entendida como um processo deliberado e intencional que visa a controlar os processos de aprendizagem para que possa consolidar, desenvolver ou redirecionar essa mesma aprendizagem" (2009, p. 67).

No que diz respeito à autorregulação, é essencial. Em concordância com Fernandes (2009) é o estudo e a percepção dos processos envolvidos no que envolve o cognitivo e o metacognitivo dos alunos, de maneira a ocorrer uma intervenção. Nessa intervenção os próprios sujeitos mobilizam-se para efetuar a regulagem de suas próprias aprendizagens.

O feedback, segundo Fernandes (2009), desempenha papel fundamental no que concerne à aprendizagem, pois precisa dar condições para que os alunos revejam estratégias utilizadas reelaborando-as para solucionar determinada tarefa. É relevante que esse feedback seja qualificado a fim de realmente dar condições para o aluno se rever, e fazer novas proposições que possam ir ao encontro do que havia sido solicitado. 


\section{AVALIAR FORMATIVAMENTE PARA QUÊ?}

Em relação às práticas de avaliação, Black e Wiliam (1998) evidenciam em seus estudos, benefícios de práticas de avaliação formativa. Para eles:

a) as práticas sistemáticas de avaliação formativa melhoram significativamente as aprendizagens de todos os alunos;

b) os alunos que mais se beneficiam de tais práticas são os que revelam mais dificuldades de aprendizagem;

c) os alunos que frequentam aulas em que a avaliação predominante é de natureza formativa obtêm melhores resultados em exames e provas de avaliação externa do que os alunos que frequentam aulas em que a avaliação é essencialmente somativa. (apud BORRALHO, LUCENA e BRITO, 2015, p. 14).

Em conformidade com os autores, é possível perceber que a prática pedagógica alicerçada em uma concepção formativa de avaliação, além de beneficiar os alunos que apresentam mais dificuldades de aprendizagem, colhe como frutos, um melhor desempenho em avaliações em larga escala. Isso porque, ao colocarmos em prática uma avaliação que se coloca como intrínseca ao processo de ensino e de aprendizagem, avaliamos diariamente os alunos e, com isso, criamos estratégias didáticas para a superação de dificuldades que ocorrem ao longo desse processo. Não ficamos esperando o final do bimestre, por exemplo, para, de posse dos resultados obtidos com a realização das provas, identificamos as não aprendizagens.

Segundo Luckesi (2011) ato de avaliar a aprendizagem, na escola, propicia um meio de tornar os atos de ensinar e aprender mais produtivos e satisfatórios. Dessa forma, é preciso que o professor associe a avaliação à sua prática pedagógica, o que ainda é um grande desafio para os docentes.

Partindo disso, a avaliação formativa pode, segundo Perrenoud:

1. Fazer evoluir o funcionamento dos estabelecimentos em direção a uma autoridade negociada, verdadeiros projetos, uma autonomia substancial, resultante de uma real responsabilidade;

2. Favorecer a cooperação entre professores em equipes pedagógicas ou em redes;

3. Agir sobre todos os parâmetros (estatuto dos professores, formação, gestão) que aumentam o grau de profissionalização do professor. (1999, p. 159).

O autor destaca a necessidade de cooperação dos envolvidos nas atividades escolares. Tanto professores como coordenadores pedagógicos precisam estudar, discutir e fazer proposições sobre os diferentes aspectos que circundam o processo de ensino, aprendizagem e avaliação. E, sobretudo, todos carecemos compreender que a avaliação é 
para a melhoria das aprendizagens.

\title{
METODOLOGIA
}

Este texto é parte integrante da pesquisa intitulada "Avaliação das aprendizagens em aulas de matemática nos anos iniciais: percepções de graduandos" que foi desenvolvida de agosto de 2017 a julho de 2019. Dela participaram 10 graduandos do curso de Licenciatura Integrada em Ciências, Matemática e Linguagens da UFPA, que cursavam a disciplina Estágio de Docência II. O estudo tinha como objetivo envolver graduandos em estudos, observações e grupos de discussão para a compreensão de diferentes concepções e instrumentos de avaliação.

Em termos metodológicos, a pesquisa teve as seguintes as etapas: estudos teóricos, observação, grupo de discussão, realização de entrevista e análise do material empírico. Ademais, a pesquisa classificou-se como de abordagem qualitativa, tendo caráter descritivo, uma vez que se interessa aos significados que os colaboradores dão às coisas. Para as análises possui enfoque indutivo.

Em consonância com Minayo

\begin{abstract}
a pesquisa qualitativa responde a questões muito particulares. Ela se preocupa, nas ciências sociais, com um nível de realidade que não pode ser quantificado, ou seja, ela trabalha com o universo de significados, motivos, aspirações, crenças, valores e atitudes, o que corresponde a um espaço mais profundo das relações dos processos e dos fenômenos que não podem ser reduzidos à operacionalização de variáveis (1995, p. 21-22).
\end{abstract}

Nos estudos aconteceram momentos de leitura e discussão de textos referentes a concepções de avaliação e a relação dessas com o processo de ensino e aprendizagem. Nestes momentos, também foram realizadas leituras que tratavam de possibilidades no que se refere à diversidade de instrumentos de avaliação.

O período de observação dos graduandos ocorreu em duas escolas públicas de Belém-PA. Foram observadas 6 turmas dos anos iniciais do Ensino Fundamental. Os graduandos foram organizados em quatro duplas e dois de forma individualizada. Foram alocadas para esse período 30 horas. Para essa observação utilizamos a Matriz de Observação do Projeto AERA ${ }^{1}$. Antes de iniciarem o período de observação, organizamos

\footnotetext{
${ }^{1}$ Projeto de cooperação internacional entre a Universidade Federal do Pará (UFPA) e a Universidade de Évora (UE-Portugal) intitulado "Avaliação e Ensino na Educação Básica em Portugal e no Brasil: relações com as aprendizagens" (AERA), aprovado, em março de 2014, pelo Edital CAPES-FCT
} 
estudo dos aspectos contidos nessa matriz.

Quadro 1 - Matriz de Investigação (AERA)

\begin{tabular}{|c|c|}
\hline Objetos & Dimenções \\
\hline \multirow{8}{*}{ Práticas de Ensino } & Organização e desenvolvimento do ensino \\
\hline & Recursos, materiais e tarefas utilizados \\
\hline & $\begin{array}{l}\text { Dinâmicas de sala de aula (e.g., trabalho de grupo; trabalho em } \\
\text { pares; } \\
\text { trabalho individual; organização das discussões) }\end{array}$ \\
\hline & Papel do professor \\
\hline & Papel dos alunos \\
\hline & Estrutura da sala \\
\hline & Percepções dos professores \\
\hline & Concepção dos alunos \\
\hline \multirow{11}{*}{ Práticas de avaliação } & $\begin{array}{l}\text { Integração/Articulação entre os processos de } \\
\text { ensino/avaliação/aprendizagem }\end{array}$ \\
\hline & $\begin{array}{l}\text { Utilizações da avaliação (e.g., para classificar, para orientar, } \\
\text { para regular, para melhorar) }\end{array}$ \\
\hline & $\begin{array}{l}\text { Instrumentos de avaliação predominantes (e.g., testes, trabalhos } \\
\text { escritos, questões orais, listas de verificação, tarefas de sala de } \\
\text { aula) }\end{array}$ \\
\hline & Natureza, frequência e distribuição de feedback \\
\hline & Dinâmicas de avaliação (e.g., Autoavaliação, Heteroavaliação) \\
\hline & Natureza da avaliação formativa (Formal e Informal) \\
\hline & Natureza da avaliação sumativa (Formal e Informal) \\
\hline & Papel do professor \\
\hline & Papel dos alunos \\
\hline & Percepções dos professores \\
\hline & Concepções dos alunos \\
\hline \multirow{4}{*}{$\begin{array}{l}\text { Aprendizagens dos } \\
\text { alunos }\end{array}$} & Participação dos alunos (dinâmicas, frequência e natureza) \\
\hline & $\begin{array}{l}\text { Percepções/Concepções dos professores/Alunos sobre os } \\
\text { contributos para a aprendizagem (e.g., tarefas, qualidade do } \\
\text { ensino, natureza e dinâmica as aulas, avaliação, feedback }\end{array}$ \\
\hline & Relação pedagógica com os professores \\
\hline & Percepções/Concepções dos diferentes intervenientes \\
\hline
\end{tabular}

Fonte: Borralho e Lucena (2015).

A matriz do projeto AERA era organizada a partir de três objetos: práticas de ensino, práticas de avaliação e aprendizagens dos alunos. Essa separação visava à organização didático-metodológica e priorizava a seleção das dimensões, orientação e direcionamento de pontos para a observação e análise. Cabe esclarecer que compreendemos que esses objetos encontram-se imbricados no processo educacional.

2013. Esse projeto teve como problema central a necessidade de se compreender as relações entre uma variedade de elementos que afetam o desenvolvimento da aprendizagem no aluno. 
Finalizado o período de observação, ocorreram os grupos de discussão. Nessa etapa, os graduandos relatavam suas percepções durante as observações. Os relatos foram mediados pela coordenadora do projeto e por mim, bolsista de iniciação científica ${ }^{2}$, com intervenções no sentido de provocar reflexões e evidenciar as percepções dos graduandos. Todas as reuniões do grupo de discussão foram gravadas e transcritas.

Para que percebêssemos os aprendizados dos graduandos a partir de seu envolvimento no projeto, decidimos pela realização de uma entrevista com dois deles. Como critério de seleção dos dois graduandos, decidimos pelos que tinham participado de todas as etapas do processo, sem nenhuma ausência nas sessões de estudos e nos grupos de discussão. Para a entrevista, elaboramos um roteiro a fim de orientar o diálogo com os graduandos. Como já mencionado, o objetivo da realização de tal entrevista foi perceber em que aspectos a participação nas atividades do projeto contribuíram para melhor compreensão das concepções e instrumentos de avaliação encontrados nas escolas observadas.

As entrevistas foram gravadas, com a devida autorização dos graduandos, e depois transcritas para constituir material de análise contidas na sequência deste texto. Optamos por identificar os graduandos como: Graduando1 e Graduando2.

Ressaltamos que, para este texto, traremos excertos das entrevistas realizadas, buscando evidenciar os aprendizados dos graduandos a partir do envolvimento nas etapas do projeto de pesquisa. Em relação ao material empírico constituídos das reuniões dos grupos de estudos e transcritos, já foram devidamente analisados e constam em Ribeiro e Marques (2019).

\section{APRENDIZADOS DOS GRADUANDOS}

Como mencionado anteriormente, neste item, faremos as análises de excertos de entrevistas realizadas com dois graduandos que participaram de todas as etapas do projeto, isso considerando até o grupo de discussão. A finalidade é evidenciar os aprendizados dos graduandos durante o envolvimento no projeto.

A primeira indagação contida no roteiro foi: "Quais estratégias eram utilizadas pelo professor para o ensino de matemática?" De acordo com os graduandos:

\footnotetext{
${ }^{2}$ Primeira autora deste artigo.
} 
A professora já estava na escola há pouco tempo, e ela tinha uma estratégia de ensino bem tradicional apesar dela ter uma formação em artes. Em matemática a gente observava (que) a prática era só exercícios de fixação, na verdade nem era tão abordada a matemática, era mais a linguagem e o que a gente viu de inovador em matemática foi um exercício, que eu acredito que ela tirou de algum site que tinha uma proposta interdisciplinar, não lembro bem os detalhes do exercicio mas a gente lembra de ser inovador para a metodologia que ela utilizava em sala de aula era bem diferente, a gente não viu ela usando essa apostila, ela disse que já tinha aplicado com os alunos mas a gente não viu como ela trabalhou com os alunos, então o que ficou eram só as aulas tradicionais de exercício de fixação, nenhum conceito nem nada, era só exercícios de fixação. (Graduandol)

As estratégias que ela utilizava eram as mesmas que eu também obtive, passar exercício no quadro e dá um tempo para resolver e tirar alguma dúvida, mas uma dúvida não direcionada, mas uma dúvida geral da turma ao perguntar "vocês entenderam?" "sim ou não". Ai (o aluno) foi resolver o exercício no caderno, levava para a professora e a professora ao final corrigia no quadro, quem resolveu, quem não resolveu na maioria dos casos apenas pegava a resposta que a professora colocava no quadro, tecnicamente era isso, era quadro, pincel e no caderno dos alunos que resolviam coletivamente. (Graduando2)

Percebemos que, de modo geral, as observações sinalizam para uma prática do ensino da matemática cuja ênfase é a utilização de exercícios, apontando como principais estratégias, a utilização da lousa e do caderno. O Graduandol destacou uma atividade isolada com uma proposta interdisciplinar, mas que fora pouco utilizada. Também é possível identificar que a docente não circulava em sala com o intuito de perceber se os alunos estavam resolvendo as atividades. Isto fica evidente no trecho "quem não resolveu na maioria dos casos apenas pegava a resposta que a professora colocava no quadro" (Graduando2).

Na sequência questionamos: "Das estratégias observadas em aulas de matemática nos anos iniciais, qual você não utilizaria e por quê?"

Eu não utilizaria essa forma apenas de usar um exercício de fixação, mesmo que seja retomado porque a gente não esteve com ela desde o início do ano, a gente não sabe se ela trabalha de outra forma, mas na retomada eu trabalharia retomando o conceito, e o exercício de fixação seria apenas uma das estratégias, não a única. (Graduandol)

O Graduando1 faz referência a não utilização exclusiva de exercícios de fixação, mas que retomaria o trabalho com o conceito do objeto matemático para, certamente almejar maior compreensão por parte dos alunos. Já o Graduando2 traz outras possibilidades:

Não utilizar essa técnica básica dela, só passar exercício no quadro para os alunos resolverem, pelo menos o tempo que eu tive lá e não vi ela utilizando 
material concreto e eu utilizaria material concreto também usava exercício do livro, eu usaria também, só que procuraria outros exercícios, vamos supor da internet ou procuraria em outros livros e outros meios de ensinar além de usar o livro didático também, e achasse necessário dependendo do desenvolver da turma, alguma atividade externa como, por exemplo, uma visita algum lugar que tivesse bastante números, vamos dizer assim, como um supermercado na questão dos preços vamos dizer assim (Graduando2).

O Graduando2 destaca que procuraria utilizar outros recursos e/ou estratégias para dinamizar as aulas de matemática. Ele agregaria material concreto, atividades retiradas da internet, exploraria o livro didático e ,possivelmente, encaminharia atividades, a exemplo da ida ao supermercado, para proporcionar um aprendizado significativo. No que se refere à aprendizagem significativa, segundo Ausubel (1982), esta ocorre quando acompanhado de uma conduta que favoreça o aluno a estabelecer associações entre os elementos novos e aqueles já presentes na sua estrutura cognitiva e encontra motivação e estímulo para de fato aprender.

No terceiro questionamento solicitamos que falassem sobre: "Quais estratégias você utilizaria para o ensino de conteúdos de matemática dos anos iniciais?" Para eles,

Eu utilizaria bastante jogos, dependendo do público-alvo, mas eu acho que do primeiro ao quinto ano os alunos ainda são bem envolvidos com jogos, com o lúdico, utilizaria bastante isso. Não só pela minha experiência nesse estágio, mas em outros quando eu ensinava para as crianças sempre tinha algo manipulável e eu percebia que isso fazia muita diferença, e elas compreendiam mais do que se eu explicasse apenas oralmente ali na frente para todo mundo. Então ia tentar fazer diversas formas em grupo, individual e coletivo, as explicações utilizando o lúdico também. (Graduando1)

Procuraria aprender outros modos, a professora na verdade estava correndo para cumprir o que a escola pedia. Mas assim, eu colocaria dessa estratégia de ensino mesmo pegar mais na questão da exposição do quadro, melhorar a abordagem, por exemplo, assim, procurar ensinar de maneiras diferentes porque eu percebi que existem aqui no curso, na questão principalmente da matemática, que para resolver uma conta, às vezes tem mais de um caminho. Não procura ensinar as crianças irem apenas por um caminho, procurar diversificar para ver se elas realmente aprendem. Alguma das vezes que eu e o parceiro, quando a gente estava no estágio, que nos foi possivel, a gente diversificava o caminho de ensinar uma mesma coisa. As crianças conseguiram compreender com mais ênfase aquele determinado assunto. (Graduando2)

Segundo o Graduando1, a aprendizagem dos alunos ocorre de diversas formas, não apenas através de aulas expositivas, mas através de outros métodos de abordagens, utilizando materiais para auxiliar o ensino, como materiais manipuláveis. Também fez referências à interação entre os alunos e entre estes e o professor, propondo atividades 
não somente individuais, como em grupos.

No que diz respeito às aprendizagens dos alunos, o Graduando2, quando diz "procurar diversificar para ver se elas realmente estão aprendendo", ressalta que uma mesma tarefa proposta pode ser abordada de diversas formas. Sendo assim, os graduandos evidenciaram um discurso sustentado por Abrantes "haverá muitas novas oportunidades para aprender e alunos diferentes aprenderam de maneiras diversas e em ocasiões diversas" (1995, p. 72).

$\mathrm{Na}$ sequência indagamos: "Quais estratégias os professores utilizavam para verificar se os alunos estavam aprendendo?"

Somente o exercício, a professora só corrigia. Nem lembro se ela dava um feedback, acredito que não, ela só corrigia. Às vezes coletivamente, às vezes só dando o visto no caderno, sem ver cada uma das questões, mas eram somente os exercícios que ela verificava. (Graduandol)

O que eu observei lá foi dos alunos que levavam o caderno. Ela observava lá o que que eles erraram e depois eu fui pensar com mais calma, nem todo mundo ela acompanhava porque às vezes tinham alunos que não levavam o caderno. Depois eu me recordei disso, e algum ou outro que ela percebia que não tinha trazido o caderno, ela chamava. Mas ai a maioria eram aqueles que estavam interessados que, corriqueiramente, levavam o caderno, mas sempre tinha aqueles que não levavam. Eles acabaram escapando da questão da aprendizagem, que ela não conseguia verificar. Ai a estratégia dela era essa, era dentro do caderno corrigir e no quadro quando ela resolvia e quando ela perguntava para algum aluno que ela escolhia individualmente, ela dizia "fulano! Você" só ele dizia. (Graduando2)

O Graduandol evidenciou, como estratégia da professora para verificar a aprendizagem dos alunos, o uso de correção de atividades em grupo, utilizando o quadro e dando visto das atividades no caderno. Já o Graduando2 destacou uma prática da professora na qual ela desenvolve essa verificação de forma individual, chamando um aluno por vez para responder, como também, utilização do visto no caderno. No entanto, é possível perceber no relato que a docente não conseguia alcançar a todos.

Também questionamos: "O que você observou no acompanhamento das aprendizagens dos alunos que você não faria em sua prática de professor que ensina matemática nos anos iniciais?"

Eu daria mais feedback para eles e faria com que eles compreendessem não somente pelo meu ponto de vista, mas desenvolvessem suas próprias estratégias e aprendessem uns com os outros. (Graduandol)

Eu procuraria na hora de resolver os exercicios no quadro coletivamente, claro que utilizaria sim a forma coletiva, mas eu procuraria buscar respostas 
mais individuais dos alunos para ver se eu tornava como costume pelo menos na minha turma nesse sentido. Porque dentro do que eu estudei, eu acredito muito na avaliação individual para melhorar o ensino, porque pelo menos buscar auxiliar aqueles alunos que estão com mais dificuldades. Também quem sabe pensar e aproveitar os alunos, dependendo de como a turma fosse unida, procurar que aqueles que soubesse um pouquinho mais ajudasse que os que sabem menos, para tentar equilibrar, o que na verdade não existe uma homogeneidade no aprendizado, pode ter no ensino, talvez, mas não na aprendizagem, que todos nós somos diferentes. (Graduando2)

O Graduando1 enfatizou que daria mais feedback aos alunos. Percebemos neste excerto que o graduando compreendeu aspectos contidos na perspectiva da avaliação formativa proposta por Fernandes (2005). Para ele, o feedback é estrutural e devidamente integrado no processo que envolve a aprendizagem dos alunos, de modo a conduzir o aluno a uma ação ou conjunto de ações.

O Graduando2 destaca o acompanhamento individualizado, com vistas a perceber e atentar para os diferentes níveis de aprendizagens encontrados em uma mesma turma. Também sinaliza para a iniciativa de favorecer uma prática que traga como viés a colaboração, em que os alunos possam ajudar uns aos outros. No que se refere ao acompanhamento individualizado, é possível compreender esta abordagem no âmbito do que propõe Perrenoud (1999) quando direciona esse tipo de acompanhamento para uma regulação no ensino, com olhar para os níveis de aprendizagem dos alunos de forma individual.

A fim de percebermos que tipo de proposição os graduandos fariam em relação a como poderiam proceder melhor acompanhamento das aprendizagens dos alunos, perguntamos: "Quais estratégias você considera que seriam mais produtivas para as aprendizagens dos alunos a partir dos conteúdos de sala de aula observados?"

Eu não tenho como dar certeza porque era mais uma visão geral, a gente passou um periodo muito curto com essa turma e a gente acabava não vendo o caderno de cada aluno, não interagindo tanto com eles pela própria prática da professora, a gente não circulava tanto em sala, mas eu arriscaria dizer que sim, essas práticas não são uma receita de bolo, mas é um ponto de partida que eu acho confortável, mas eu precisaria conhecer mais eles para ver exatamente que estratégias. (Graduando1)

Quanto à utilização de estratégias para o trabalho com os conteúdos de matemática, o Graduando1 ressalta a importância de conhecer o perfil da turma para então, proceder com as estratégias necessárias para a melhor aprendizagem dos alunos.

Para o Graduando2, 
Utilização de material palpável, material dourado, uma diversificação de recursos, isso eu cheguei a ver, a utilização de vídeo, se fosse possível, a questão dos slides e uma abordagem na questão da matemática pro dia a dia, pra ficar mais interessante o ensino, para que eles observassem que tem serventia, pois o aluno dizia "ah, aprendi algoritmo puro" como ocorria lá e também isso cause desinteresse, mudar a abordagem para se tornar mais interessante. (Graduando2)

O Graduando2 destaca que diversificaria a utilização de recursos para o trabalho com a matemática. Referencia que é necessário que os alunos não se restrinjam à compreensão do algoritmo puro, mas que consigam utilizar esse algoritmo em diferentes atividades com que se deparam no cotidiano.

Em relação ao que o professor usava para avaliar, indagamos: "Quais instrumentos de avaliação o professor utilizava para proceder à avaliação das aprendizagens?"

Somente a prova e os exercicios, acredito que tinha uma somatória de vistos e as provas bimestrais, mas fora isso não via outro tipo de avaliação. (Graduando1)

De acordo com o excerto da fala do Graduando1, percebemos uma prática de avaliação em que a prova e a somatória de vistos no caderno são suficientes para se proceder a avaliação. A prática observada por esse graduando aproxima-se do que Fernandes (2009) propõe como avaliação somativa, em que se está preocupado mais com o resultado final, com o indicar ao pai, se o aluno foi aprovado ou reprovado. Essa perspectiva vislumbra a certificação dos alunos, a atribuição de classificação e seleção.

E acrescentamos, "Do que foi observado em termo de avaliação das aprendizagens, o que você não utilizaria em suas práticas em turmas dos anos iniciais?"

Não digo que eu não utilizaria, mas não utilizaria somente os exercícios ou somente a prova, utilizaria as discussões em grupos, como falei, uma proposta seria trabalhar em equipe e essas discussões seriam válidas para avaliação como eles desenvolvessem as estratégias, como eles pudessem chegar no resultado seria avaliado, o comportamento deles, não somente no conteúdo em si, acredito que o comportamento seja importante para aprendizagem em geral, trabalho em equipe, trabalhos individuais, formas de explicações apresentadas ou individuais quando chamados. (Graduandol)

Nesse sentido, o Graduando1 evidenciou a relevância de não optar pela utilização da prova como o principal meio para proceder a avaliação. Dessa forma, aproxima-se de aspecto condizente com a concepção de avaliação formativa alternativa (FERNANDES, 2009), assim como, para poder melhor identificar os níveis de aprendizagens dos alunos 
empregando outras abordagens como trabalhos em grupos ou individuais e com a utilização de instrumentos variados, tal como propõe Mondoni (2008).

O Graduando2, ao ser indagado sobre: "Que instrumentos você utilizaria para a avaliação dos seus alunos?" Respondeu:

Uma abordagem dos alunos de forma oral, vamos supor, quando passar o exercício no quadro ia caminhar durante a resolução do exercício, perguntando para os alunos o que eles tinham mais dificuldade, procurando explicar de novo se fosse necessário, mas fazer de uma maneira individual, que isso a professora não fazia, não era bem visível, procurar fazer uma abordagem mais individual e não tanto coletivo. (Graduando2)

O Graduando2 enfatiza que daria atenção a uma prática que conseguisse dar orientação individualizada aos alunos, procurando identificar dificuldades, de modo a não permitir a continuidade dessas dificuldades, mas procurando explicar novamente ou, possivelmente, utilizando de outra estratégia metodológica para isto. No excerto, o graduando não sinalizou para nenhum instrumento que poderia utilizar.

Para o Graduando1, solicitamos que falasse sobre que aprendizagens foram favorecidas a partir de sua participação no projeto, em especial, no que se refere aos estudos de concepções e estratégias vistas. Mencionou:

Entendia uma visão geral não tão detalhada ensino-aprendizagem-avaliação, tanto é que nos nossos planos de aula não tinha um tópico somente para a avaliação, e a partir desse momento, do projeto, a gente passou a observar isso e colocou no nosso plano de aula uma ênfase maior, não há visão geral, mas essa questão do feedback, essa questão de outras estratégias a lenda da prova para avaliar. (Graduando1)

E acrescentou,

Foi uma coisa que me esclareceu, na verdade eu não tinha tanto conhecimento a respeito de avaliação ensino-aprendizagem juntos, então as leituras somaram para eu pensar em outras estratégias de avaliação. (Graduando1)

De acordo com o Graduando1, sua participação no projeto permitiu amadurecimento de sua compreensão acerca da indissociabilidade do ensinoaprendizagem-avaliação. Além disso, destaca que compreendeu que é possível avaliar a partir da utilização de outras estratégias e/ou instrumentos que não apenas e exclusivamente a prova.

\section{CONSIDERAÇÕES FINAIS}

A avaliação configura-se como uma tarefa difícil não só para quem está sendo 
avaliado, mas para quem avalia. Nesse sentido, através dos estudos e das análises realizadas, verificamos que os professores das escolas frequentadas pelos graduandos colaboradores da pesquisa, ainda enxergam a avaliação dissociada do processo de ensinoaprendizagem, o que acaba por limitar suas práticas. No que se refere aos instrumentos utilizados para avaliar, identificamos a prevalência da prova.

O desenvolvimento do projeto junto aos graduandos que frequentaram o tema Estágio de Docência II foi um aspecto relevante, pois a formação inicial precisa propiciar o envolvimento desses graduandos com estudos que permitam a compreensão de diferentes aspectos pedagógicos, didáticos e de conteúdos que fundamentem uma prática que dê condições de todos os alunos aprenderem com qualidade. Os estágios, neste sentido, precisam ser encaminhados de modo que eles não apenas observem, mas, sobretudo, que reflitam e proponham a partir da realidade diagnosticada.

Por meio dos relatos dos graduandos, evidenciamos um grande aprendizado em relação a três aspectos: a ampliação dos conceitos relacionados à avaliação formativa; percepção sobre indissociabilidade entre ensino-aprendizagem-avaliação e ampliação do conhecimento de instrumentos de avaliação. Nesse sentido, o objetivo proposto neste trabalho foi alcançado em termos de favorecer a discussão sobre as práticas de avaliação dos professores de escolas estaduais dos $4^{\circ}$ e $5^{\circ}$ anos, como também, proporcionar ampliação sobre as discussões referente a avaliação formativa para discentes do curso de Licenciatura Integrada em Ciências, Matemática e Linguagens da UFPA, de modo que consigam, em suas práticas pedagógicas, identificar, adequar e proceder uma avaliação que cuide das aprendizagens dos alunos.

\section{REFERÊNCIAS}

ABRANTES, Paulo. Avaliação e educação matemática. Rio de Janeiro: GEPEM, 1995. (Série Reflexões em Educação Matemática, v. 1).

ALVES, Kelly Bomfim. Práticas avaliativas de professores que ensinam matemática nos anos iniciais do ensino fundamental em Rondonópolis - MT. Dissertação (Mestrado em Educação) - Universidade Federal de Mato Grosso - MT, 2016.

AUSUBEL, D. P. A aprendizagem significativa: a teoria de David Ausubel. São Paulo: Moraes, 1982.

BLACK, P.; WILLIAM, D. Assessment and classroom learning: Assessment in 
Education: Principles, Policy \& Practice. Mar 1998, vol. 5, Issue 1.

BORRALHO, A. M. Á.; LUCENA, I. C. R.; BRITO, M. A. R. de B. Avaliar para melhorar as aprendizagens em matemática. Coleção IV - Educação Matemática na Amazônia - V. 7. Belém: SBEM-PA, 2015.

BORRALHO, A, LUCENA, I. C. R. Avaliação e Ensino na Educação Básica em Portugal e no Brasil: relações com as aprendizagens (AERA). In: VI Seminário Internacional de Pesquisa em Educação Matemática, 2015, Pirenópolis-GO: Anais do VI Seminário Internacional de Pesquisa em Educação Matemática, Pirenópolis-GO, 2015.

CALZAVARA, Maria Tereza Santos. As práticas avaliativas e os registros de resultados nos anos iniciais do ensino fundamental: um estudo de caso. Dissertação (Mestrado em Educação) - Universidade Federal do Estado do Rio de Janeiro, Rio de Janeiro-RJ, 2011.

CATANI, D. B.; GALLEGO, R. C. Avaliação. São Paulo: editora UNESP, 2009.

FERNANDES, D. Avaliar para aprender: fundamentos, práticas e políticas. São Paulo: editora UNESP, 2009.

FERNANDES, D. Avaliação das aprendizagens: desafios às teorias, práticas e políticas. Lisboa: Texto Editora, 2005.

HOFFMANN, Jussara. Avaliação Mediadora: Uma Prática em Construção da Préescola. A Universidade. 14 ed. Porto Alegre: Mediação. 1993.

LIBÂNEO, José Carlos. DIDÁTICA. São Paulo: Cortez, 2a edição,1994.

LUCKESI, C. C. Avaliação da aprendizagem: componente do ato pedagógico. $1^{\mathrm{a}}$ ed. São Paulo. Cortez, 2011.

MARQUES, Washington Campos. Narrativas sobre a prática de ensino de matemática de professores dos anos iniciais do ensino fundamental. Dissertação (Mestrado em Educação Matemática) Universidade Est. Paulista Júlio De Mesquita Filho, Rio Claro-SP, 2013.

MINAYO, M. C. S. (Org.). Pesquisa Social: Teoria, Método e Criatividade. Petrópolis: Vozes, 1995.

MONDONi, M. H. A. O Processo da Avaliação no Ensino e na Aprendizagem de Matemática. Dissertação (Programa de Pós-Graduação em Ensino de Ciências e Matemática) - Universidade Cruzeiro do Sul, São Paulo/SP, 2008.

PERRENOUD, P. Avaliação: da excelência à regulação das aprendizagens - entre duas lógicas; trad. RAMOS, P. C. Porto alegre: artes médicas sul, 1999.

RIBEIRO, Fábio, MARQUES, Valéria Risuenho. Avaliação das aprendizagens: entre o dito e o praticado. Revista Cocar. V.13. N. 27. Set./Dez./ 2019 p. 768-783. 
SANTOS, Noemia das Graças Rodrigues dos. Práticas Avaliativas no contexto dos anos iniciais: acontecimentos, circunstâncias e significados para refletir sobre a própria prática. Dissertação (Mestrado Profissional em Docência em Educação em Ciências e Matemáticas) - Universidade Federal do Pará, Belém-PA, 2016.

SANTOS, Débora Guimarães Cruz. A matemática na formação de professoras dos anos iniciais do ensino fundamental: saberes e práticas. Dissertação (Mestrado em Ensino de Ciências e Matemática) - Universidade Federal de Sergipe-SE, 2012.

SILVA, J. F. Avaliação na perspectiva formativa-reguladora: pressupostos teóricos e práticos. Ed. Medição, 2004.

Submetido em 26 de março de 2020. Aprovado em 27 de junho de 2020. 